\title{
Training Assistant for Industrial Processes through Augmented Reality
}

\author{
Jonathan A. Romero, Washington D. Quero, Jorge S. Sánchez, Víctor H. Andaluz \\ Universidad de las Fuerzas Armadas ESPE \\ \{jaromero12, wdquero, jssanchez, vhandaluz1\}@espe.edu.ec
}

\begin{abstract}
This article presents an application of augmented reality, as a contribution to the industrial and education sector, through a technological tool for the assistance of operators in industrial processes. It facilitates the identification of equipment and instruments, granting the management and visualization of the parts constitutive of the elements of the process. Additionally, it guides in the calibration of instruments and the simulation of a closed loop control algorithm that allows control by regulation. Its development focuses on the recognition of equipment through a Smartphone for detect characteristic points of objects and image recognition, 3D modeling through CAD software and integration in a multiplatform, incorporation of animations and mathematical modeling of industrial processes that allows of the development of closed loop control algorithms. The tests performed on the augmented reality application demonstrated an easy handling and high interactivity with the user. The results provide greater knowledge in the operation and structure of the equipment, instrument and process. Finally, the results support the skills development for the tuning of PID controllers in industrial processes.
\end{abstract}

\section{CCS Concepts}

- Applied computing $\rightarrow$ Education

- Human-centered computing $\rightarrow$ Visualization systems and tools

\section{Keywords}

Augmented reality, 3D animation, PID Control.

\section{INTRODUCTION}

Technology is a set of tools created by and for humans. It follows an important tendency to affect the day-to-day of societies and industries, promoting the digital revolution and sociocultural changes [1]. Currently, technological activity is diverse, allowing the perception of computational elements and objects within our experience of the real world [2]. These technological developments have strongly influenced several areas of industry by creating new tools for training and assisting staff within the industrial sector [3].

Augmented reality, AR is a technology that extends the images of reality through a technological device, adding virtual elements such as video, texts or 3D models to provide a mixed reality. In recent years, it has been an important contribution to the fields of industrial manufacturing and simulation of equipment and products

\footnotetext{
Permission to make digital or hard copies of all or part of this work for personal or classroom use is granted without fee provided that copies are not made or distributed for profit or commercial advantage and that copies bear this notice and the full citation on the first page. Copyrights for components of this work owned by others than ACM must be honored. Abstracting with credit is permitted. To copy otherwise, or republish, to post on servers or to redistribute to lists, requires prior specific permission and/or a fee. Request permissions from Permissions@acm.org. ICETC 2019, October 28-31, 2019, Amsterdam, Netherlands (C) 2019 Association for Computing Machinery. ACM ISBN 978-1-4503-7254-1/19/10.. \$15.00 DOI: doi.org/10.1145/3369255.3369295
}

[4]. Despite the upward trend of augmented reality in the industrial sector, it is usually aimed for research purposes only [5] [6]; it means that the transfer of the industrial environment is still limited [7]. The applications are widely established according to specific tasks and ergonomic requirements [8]

The applications developed in augmented reality can be divided into three groups. First, applications that allow the identification of objects and show multimedia information [9-14]. In [9] the application is oriented to the process of training and assistance of equipment and industrial instruments within the engineering fields where it provides general information and multimedia links. In [10] the application focuses on education where it provides specific information of each chemical element to simplify the understanding of chemical bonds and molecules. The application developed allows to obtain specific information such as: constituent parts of equipment, instrumentation or process, real-time value of the controlled variables of the process and component information of P\&ID diagrams. Second, applications with animation, providing more realism and interactivity [15-21]. In [15], animations are integrated to show the components and how they should be assembled into a car power generator. In [16] animation is used with narrations as a teaching technique in a mixed learning environment. The application proposed through animation allows us to observe: the operation of each equipment and industrial instrument, and the evolution of the variables of interest in the algorithm of control. And finally, the applications designed to provide security [22-25]. In [22], the information to perform a procedure is displayed sequentially to verify the security. The application generated allows to know the process in any required time and to coordinate the algorithm of control, which reduces risk at workplace caused by lack of training.

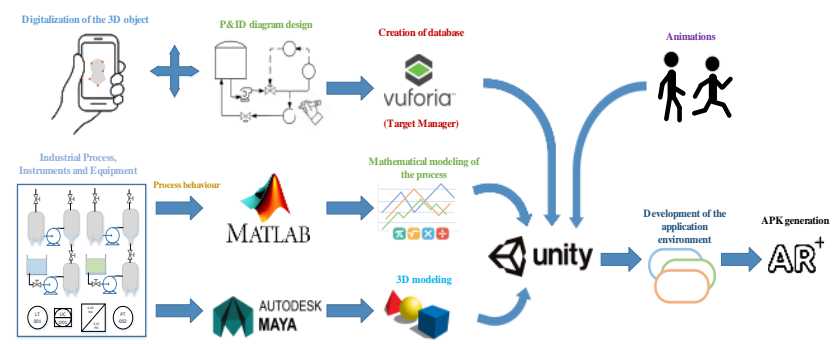

Figure 1. Workflow for the development of the proposed AR application

This article aims to provide assistance in industrial processes through the development of an AR application. In the industrial environment with physical access to the process, the application allows the 3D recognition of industrial equipment and instruments, and support in the calibration of the instruments through animations with narration. When the environment does not provide physical access to the process, the application allows the $2 \mathrm{D}$ recognition of P\&ID diagrams, management of the process elements by means of virtual buttons, internal and external visualization of the instrument 
through animation clips. In addition, the simulation of the industrial process by implementing an algorithm of control that allows us to maintain the process variable at a value equal to or close to the one desired by the user. All these factors will provide a realistic feeling in the interaction with the object and the process. Figure 1 describes the workflow that allows the development of the proposed AR application.

This article is divided into VI sections, including the Introduction. The second Section details the recognition techniques used and the creation of the database. In the third Section, the mathematical model and the parameters for the implemented algorithm of control are detailed. The fourth Section details the characteristics of the AR application environment, 3D development and add of animations. In the fifth Section are detailed the results obtained by using the AR application using a smartphone and its respective analysis of results. Finally, the sixth Section describes conclusions.

\section{RECOGNITION TECHNIQUES}

In this section the two recognition techniques used are detailed: $3 \mathrm{D}$ and $2 \mathrm{D}$, and the creation of the database of the markers to be used in the multiplatform. For the 3D recognition, the object is scanned and for the $2 \mathrm{D}$ re-knowledge it is necessary to create the P\&ID diagram of the process.

\subsection{Digitalization of the 3D Object}

The identification of different equipment and industrial instruments is a main part of this work; a good identification method will allow the instrument to be instantly recognized in the AR application; in order to meet this objective, the digitization of the instrument is obtained through the application for Smartphone known as Vuforia Object Scanner, which focuses on the processing of objects determining characteristic feature points and regions of them. This digitization technique provides good results in the recognition in terms of repetitiveness and robustness.

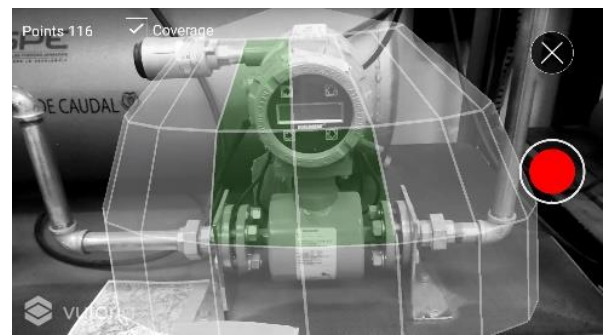

Figure 2. Acquisition of the characteristic points of an object

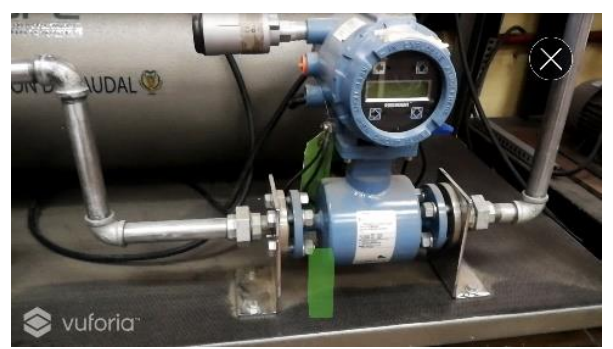

Figure 3. Test to check the correct recognition pattern. Creation of database

For the recognition of equipment and instruments, a coordinate system is established as a reference, which is located around the object to detect and track the physical characteristics it possesses (opaque, rigid, with moving parts, etc.). The progress of the scanning task to the place where the equipment or instrument is submitted is observed in real time, as well as obtaining the number of points and the characteristic region, as indicated in Figure 2.
Finally, it is possible to obtain a file of recognition pattern. The validation of the recognition pattern through the extraction of characteristic points is carried out by means of a test, through the Vuforia Object Scanner application, as shown in Figure 3.

The set of markers obtained is loaded in Target Manager of Vuforia Developer Portal. This web tool allows to create and manage online databases, in order to generate a file that can be reached directly with the Unity multiplatform, in order to be used in the recognition within the AR application.

Inside the Target manager you can identify the characteristic features of each image by enabling the Show Feature option, the more defined the image and the more points generated, the better the recognition.

\section{MATHEMATICAL MODELING}

For practical case, an experimental research is carried out for very common processes within the industry, such as: flow and pressure.

In order to get a good mathematical model, defined inputs are introduced to study the output of the system, a test is carried out between the voltage applied to the frequency inverter that is connected to the pump V, and the flow that contributes to the system Q. Figure 4 shows the graph of the behavior of the flow process at different desired operation values.

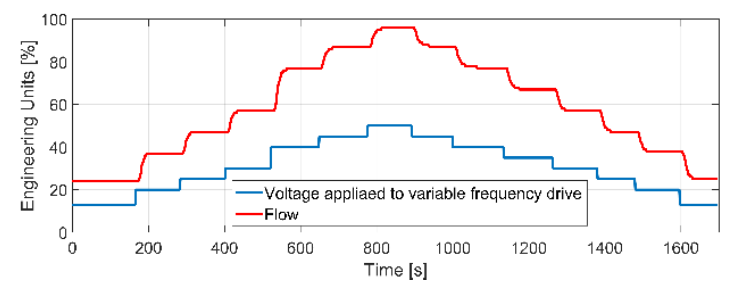

Figure 4. Flow process behavior

The behavior of the process in the frequency domain is represented by MatLab software, obtaining the expression of a first-order system (1), in addition to obtaining the parameters of the PID control algorithm.

$$
Q_{\text {out }}(s)=\frac{1.9211}{1.2168 s+1} e^{-0.7023 s}
$$

Expressing temporarily:

$Q_{\text {out }}(t)=\frac{19211 \text { heaviside }\left(V-\frac{7023}{10000}\right) \exp \left(\frac{2341}{4056}-1250 \mathrm{~V}\right)}{1521}$

Table 1 indicates the control parameters for the flow process, obtained by applying the tuning methods in linear processes of the first order [27].

Table 1. Control parameters for the flow process

\begin{tabular}{|l|c|c|c|}
\hline Method - Parameter & Kp & Ki & Kd \\
\hline Ziegler Nichols & 2.079 & 1.4046 & 0.3511 \\
\hline López & 0.1716 & 1.6917 & 1.0555 \\
\hline
\end{tabular}

The validation for the flow process is performed by comparing the data obtained experimentally versus the simulation performed by MatLab. Figure 5 shows the response of the actual flow process to different adjustment methods vs. the adjustment methods with the model obtained. 


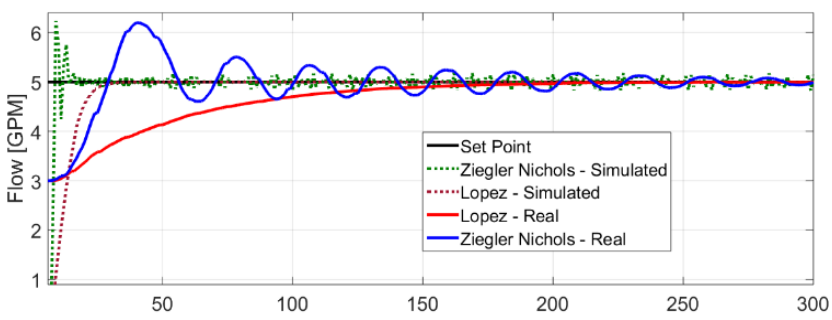

Figure 5. Response of the real vs simulated flow process to different adjustment methods

In the process of pressure in the same way an experimental test is carried out, obtaining the system temporarily:

$$
P_{\text {out }}(t)=\frac{397 \text { heaviside }\left(I-\frac{5257}{50000}\right) \exp \left(\frac{751}{50805}-\frac{1000 I}{71127}\right)}{11290}
$$

Considering that: I current applied to the I/P converter, $\mathrm{P}$ pressure output system.

Table 2 indicates the control parameters for the pressure process, obtained by applying the tuning methods in first order linear processes.

Table 2. Control parameters for the pressure process.

\begin{tabular}{|l|c|c|c|}
\hline Method - Parameter & Kp & Ki & Kd \\
\hline Ziegler Nichols & 32.4576 & 2.1089 & 0.5257 \\
\hline Lamba Agresivo & 0.3998 & 71.6527 & 0.5218 \\
\hline
\end{tabular}

Validation for the pressure process is performed by comparing the data obtained experimentally versus the simulation performed by MatLab. Figure 6 shows the response of the actual pressure process to different adjustment methods vs. the adjustment methods with the model obtained.

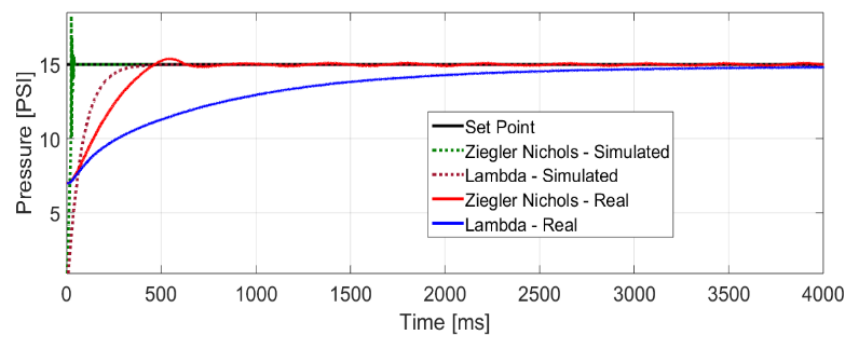

Figure 6. Response of the real vs simulated pressure process to different adjustment methods

The implementation of the plant's behavior is done by means of a script with (2) and (3) for the flow and pressure processes respectively, as well as the algorithm of control the parameters obtained according to Tables 1 and 2 .

\section{ENVIRONMENT AND ANIMATIONS}

This Section describes the interface developed for the AR application: 3D development and incorporation into Unity, characteristics of the environment and the development of animations.

\subsection{D Development and Incorporation to Unity}

To provide an intuitive interface that allows the user a friendlier interaction with the equipment or instrument, it is necessary to provide volume, texture, color, etc. The use of CAD software allows us to provide these features, the $3 \mathrm{D}$ development of the instruments is carried out in Maya Autodesk; Maya is a multiplatform program designed specifically for the development of 3D graphics, animation, rendering, special effects, etc. [27]

In CAD development, the details and characteristics of the object are determined, to provide realism, use the data sheet of each instrument and industrial equipment, Figure 7 shows a didactic flow station in front of a flow station developed in Maya and imported to Unity. The different CAD models of industrial instruments and equipment must be exported in. FBX format.

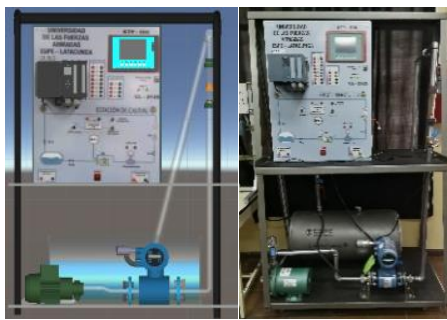

Figure 7. Simulated plant vs real flow plant

In the incorporation of developed 3D models, for 3D recognition it is necessary to insert a primitive object (cube, sphere, cylindrical capsule) and link it to the corresponding marker in the Objective section of the object; for $2 \mathrm{D}$ recognition, the $3 \mathrm{D}$ model is linked to the corresponding marker in the Image objective section.

\subsection{Development of the Environment of the AR Application}

In order to allow an intuitive navigation in the mobile application, 3 scenes are incorporated: main, secondary and simulation. The buttons used for the development of the application are presented in Table 3.

Table 3. Buttons of the AR application

\begin{tabular}{|c|c|c|}
\hline Name & Icon & Action \\
\hline Information & (i) & $\begin{array}{l}\text { Window display through animation that contains } \\
\text { the description of the action the each button } \\
\text { present in the scene. }\end{array}$ \\
\hline Screen & $(+?)$ & Take a screenshot and save it on the Smartphone. \\
\hline Plus & & $\begin{array}{l}\text { Deployment of other options that can be } \\
\text { performed through animation, depending on the } \\
\text { scene. }\end{array}$ \\
\hline Play & & Start the animation (Operation of the instrument). \\
\hline Stop & & Pause the animation. \\
\hline Expand & & Start the animation (Instrument structure). \\
\hline Process & & $\begin{array}{l}\text { Navigate to the simulation scene from Object } \\
\text { Target. }\end{array}$ \\
\hline Calibration & & $\begin{array}{l}\text { Start the animation (Calibration of the } \\
\text { instrument). }\end{array}$ \\
\hline Model & 3D & Visualize the 3D model. \\
\hline Control & & $\begin{array}{l}\text { Navigate to the simulation scene from the Image } \\
\text { Target. }\end{array}$ \\
\hline $\begin{array}{l}\text { Control } \\
\text { PID }\end{array}$ & CONRad & Modify the control parameters. \\
\hline Graphics & A & View the trend graphs of the process variables. \\
\hline
\end{tabular}




\begin{tabular}{|c|c|c|}
\hline P\&ID & PSID & View the P\&ID diagram. \\
\hline Return & 3 & Return to the previous scene. \\
\hline Exit & (1) & Exit application. \\
\hline
\end{tabular}

1) In the main scenario the recognition of $3 \mathrm{D}$ objects is implemented, its environment in Unity is observed in Figure 8.

2) In the secondary scenario, $2 \mathrm{D}$ recognition is implemented, its environment contains virtual buttons (transparent boxes located in the P\&ID diagram) and can be seen in Figure 9.

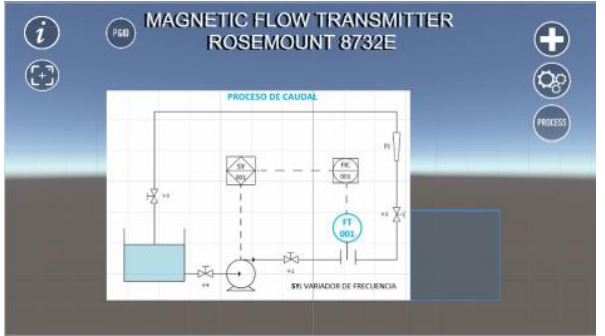

Figure 8. Development environment in Unity of the Rosemount 8732E Transmitter

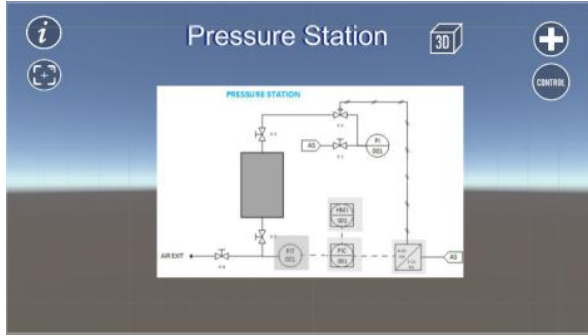

Figure 9. Unity development environment of the Pressure Station

3) In the simulation scenario the process simulation and algorithm of control is implemented, its main environment is observed in Figure 10.

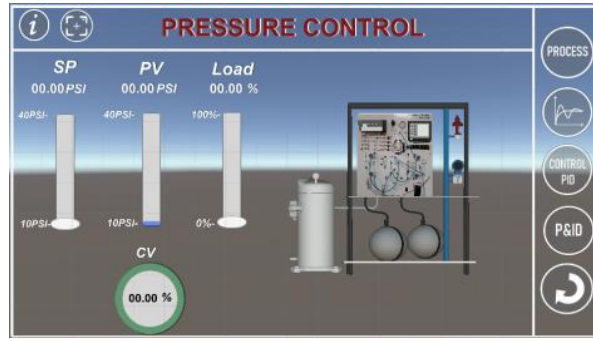

Figure 10. Simulation Scene environment in Unity pressure process

To provide greater intuition to the application, animation clips are developed that allow you to obtain information about some objects in real time, which allows you to change their position, rotation and other properties. The generated animations provide information similar to a flowchart, which allows you to independently organize each animation action that the object will perform. This allows you to easily link the animation to the enhanced environment.

\section{EXPERIMENTAL RESULTS}

This section presents the augmented reality interface and the usability that it has as a technological tool for the assistance of operators in industrial processes, which facilitates the identification of $3 \mathrm{D}$ equipment and instruments identification, the guidance in calibration of industrial instruments, as well as the simulation of a control algorithm that allows the variable of the process to be maintained at a value equal to or close to that desired by the user. To start with the application, it is necessary to previously install the APK on the Smartphone.

The use of the augmented reality application on a mobile device by the user is seen in Figure 11. To perform 3D recognition, the first step is for the user to concentrate on the equipment or instrument. When recognized, it shows that it is the S7-1500 PLC and when the "P\&ID" button is pressed, the P\&ID diagram of the process to which it belongs is shown as shown in Figure 12.

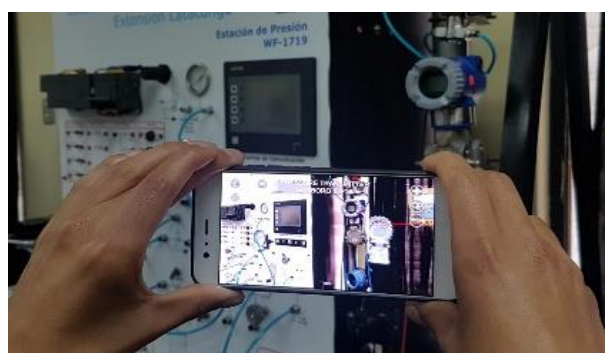

Figure 11. Use of the application on the smartphone by the user

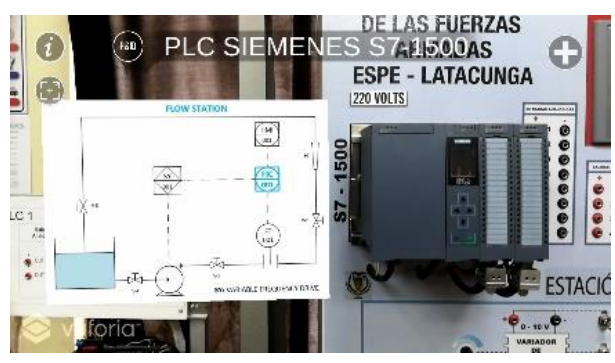

Figure 12. Recognition of the S7-1500 PLC

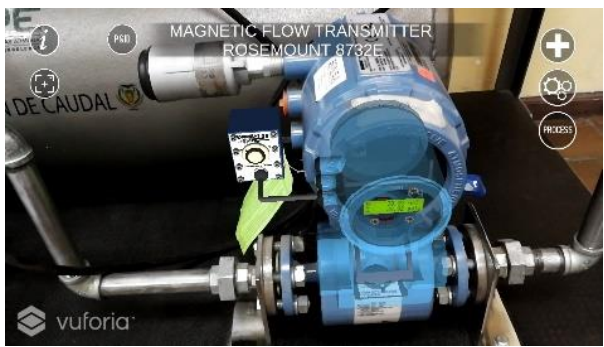

Figure 13. Calibration of the Rosemount 8732E transmitter

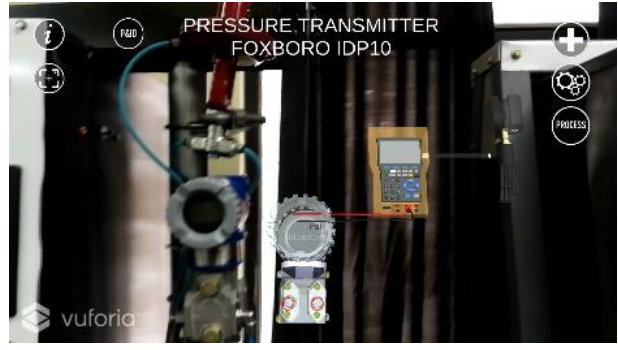

Figure 14. Calibration of the Foxboro IDP10 transmitter

By recognizing the Rosemount $8732 \mathrm{E}$ Transmitter and clicking on the "calibration" button, the animation that describes the calibration form of the instrument is started, as shown in Figure 13. Similarly, Figure 14 shows the calibration of the Foxboro IDP10 Transmitter. The "process" button allows navigation to the simulation scenario, 
Figure 15 shows the information window displayed by animation by clicking on the "information" icon".

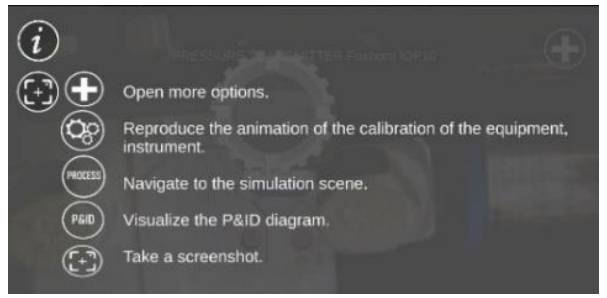

Figure 15. Scene button information

To perform 2D recognition, the first step is for the user to focus on the image of the process diagram, when the diagram is displayed by text, that is, from the pressure station, the "model" button allows the $3 \mathrm{D}$ model to be displayed of the plant, move, scale or rotate according to the user's needs, as can be seen in Figure 16.

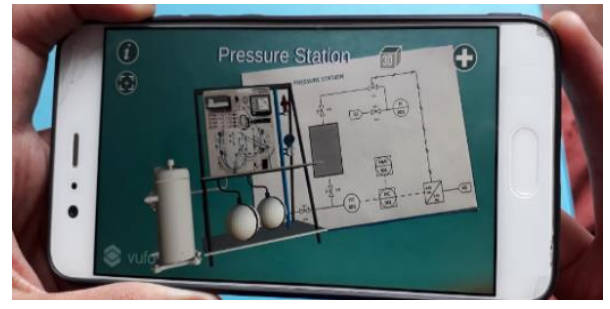

Figure 16. User using the application with the pressure process

When the "PIT-001" icon is selected, the Foxboro IDP10 transmitter is moved by animation, as shown in Figure 17. A new window is opened that allows using the "expand" button to execute the animation of the constitution of the instrument as shown in Figure 18.

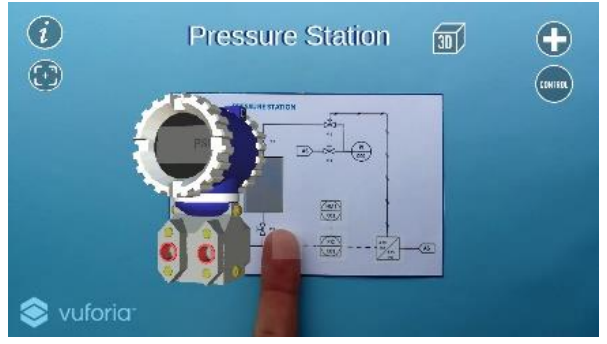

Figure 17. 3D model by placing your finger on the virtual button of the pressure P\&ID diagram

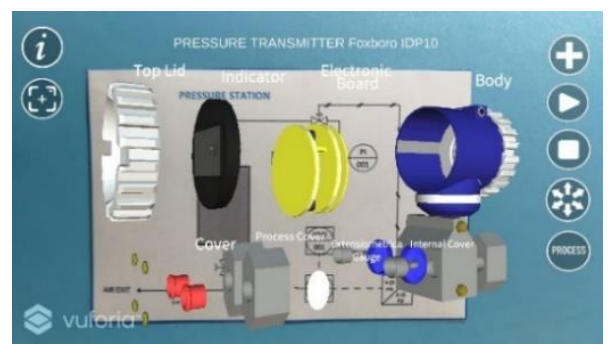

Figure 18. Animation constituent parts of the Foxboro IDP10

Similarly, by selecting the "FIT-001" icon of the flows diagram, the Rosemount $8732 \mathrm{E}$ transmitter appears animating. After clicking on the "play" button, the operating principle of the instrument is executed by means of animation, as shown in Figure 19, when the "process" icon is clicked it is possible to navigate through the simulation scene.

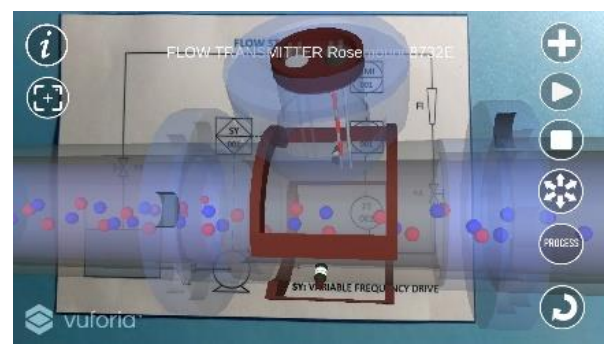

Figure 19. Animation of the operating principle of the Rosemount 8732E transmitter

In the simulation scene, the SP and Load sliders can be manipulated, Figure 20 shows the flow station off. Figure 21 shows the station turned and scaled, as well as the pipes are full and water falls into the tank when the SP is greater than 0 GMP.

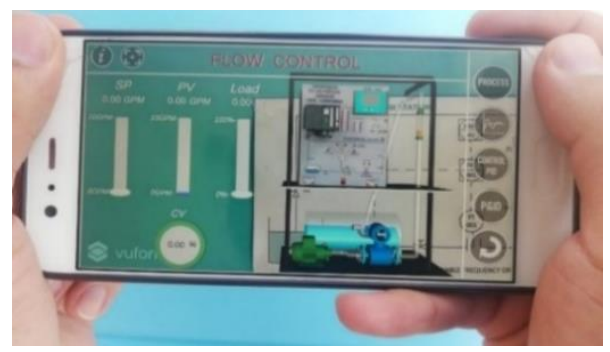

Figure 20. Flow station off, use of the application by the user

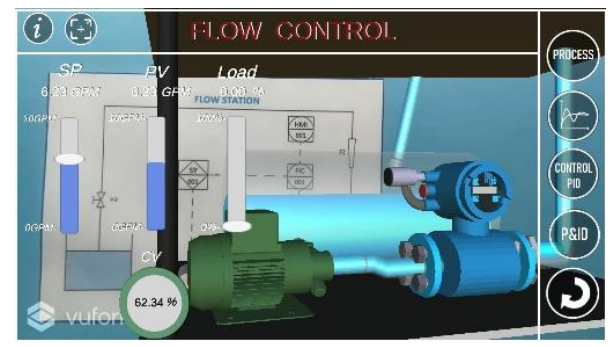

Figure 21. 3D model flow process rotated and scaled

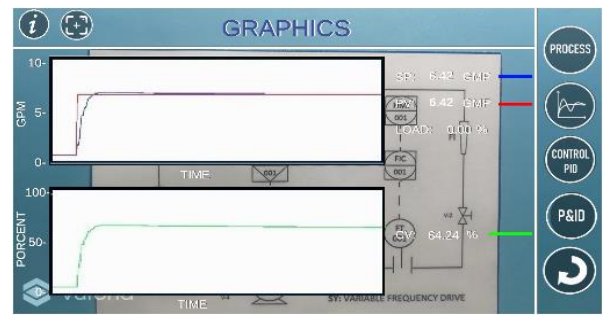

Figure 22. Graph of the process variables with an SP of 6.43 GMP

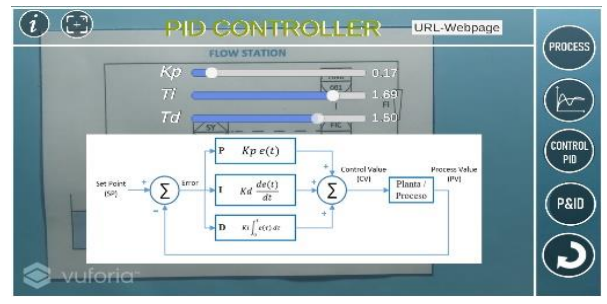

Figure 23. Control Parameters

The graphs of the trends of the SP, PV and CV values can be observed by clicking on the "graphics" button as indicated in Figure 22. By clicking on the "PID Control" icon, the values of the Kp, Ti and Td slider controls can be modified, as shown in Figure 23. 
Clicking on the "P\&ID" icon shows the P\&ID diagram. When you click on the "URL-Web Page" button, an Internet page opens to provide more information about P\&ID diagrams or PID control respectively.

Figure 24 shows the response graph for $\mathrm{SP}=5.06 \mathrm{GPM}$ to the flow model implemented in the application with the control algorithm with a Load $=10 \%$, Figure 25 shows the Real plant behavior with the same control parameters $(\mathrm{Kp}=0.1716, \mathrm{Ti}=$ 1.6917, $\mathrm{Td}=1.0552$ ).

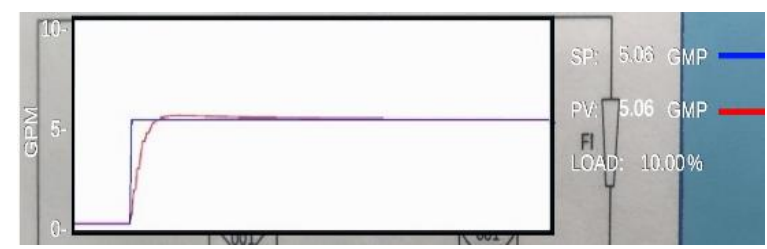

Figure 24. Flow process behavior in the AR application

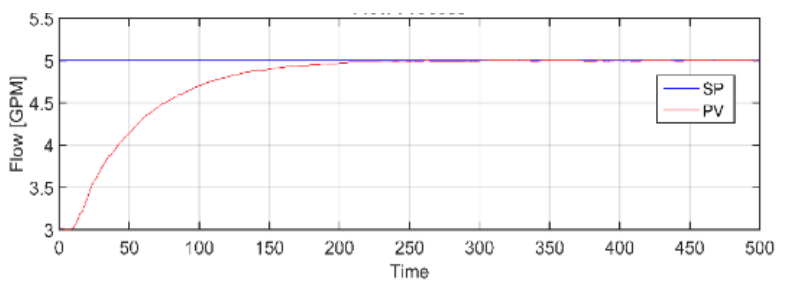

Figure 25. Real flow process behavior

Figure 26 shows the response graph for SP $=25.48$ GPM to the pressure model implemented in the application with the control algorithm with a Load $=20 \%$, Figure 27 shows the Real plant behavior with the same control parameters $(\mathrm{Kp}=0.3998, \mathrm{Ti}=$ $71.6527, \mathrm{Td}=0.5218)$.

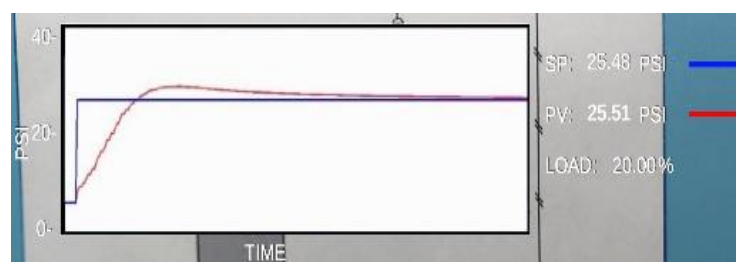

Figure 26. Pressure process behavior in the AR application

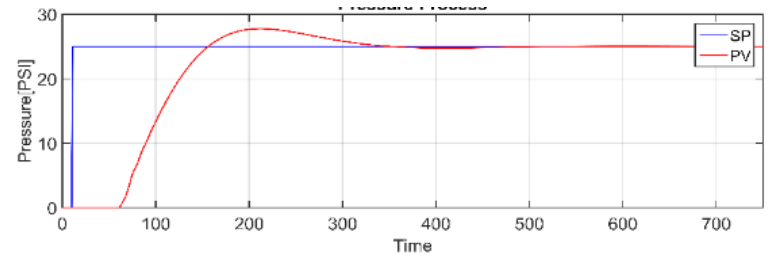

Figure 27. Real pressure process behavior

The results presented below indicate the validity of the usability of augmented reality environments, for this specific case: the process of operator assistance in the handling and calibration of instruments and tuning of a control algorithm. For this purpose, the SUS summary evaluation method is used [28] with 40 people as participants (30 engineering students and 10 technology students). focused on measuring the reliability of the application to meet the objective for which it was developed, this providing a single number a general usability scale of the smartphone application for the navigation, calibration and simulation of the control algorithm, as shown in Table 4.

Table 4. Results of the questionnaire

\begin{tabular}{|c|c|c|c|c|c|c|}
\hline Questions & \multicolumn{5}{|c|}{ Punctuation } & Operation \\
\hline I would like to use the application frequently & & & & 6 & 34 & 3.85 \\
\hline I found the app with augmented reality is unnecessarily and complex. & 10 & 18 & 12 & & & 2.95 \\
\hline It was easy to use the app with augmented reality. & 2 & 8 & 15 & 7 & 8 & 2.275 \\
\hline I think I need the support of a technician to be able to use this application. & 15 & 14 & 11 & & & 3.1 \\
\hline The different functions of the application are well integrated. & & & & & 40 & 4 \\
\hline I thought the application was confusing. & 11 & 17 & 12 & & & 2.975 \\
\hline I realized that most people would learn very quickly to use the application. & & & 1 & 20 & 19 & 3.45 \\
\hline I found the application very difficult to use. & 15 & 16 & 9 & & & 3.15 \\
\hline I felt very confident in the navigation of the application. & & & 6 & 20 & 14 & 3.2 \\
\hline I need to learn many things before using the application. & 2 & 13 & 16 & 9 & & 2.2 \\
\hline TOTAL & & & & & & 31.45 \\
\hline
\end{tabular}

The totality, obtained from the sum of the operation in each question, gives 31.45 as result; based on this result, the SUS score is calculated and expressed by a multiplication of 2.5. It means that the application is very useful for training and for giving assistance in the handling of industrial equipment and instruments, providing assistance to the operator, obtaining a percentage of $79 \%$, representing a high usability of this type of technological tools. For more precision in the detection of objects and images is necessary to consider lighting in which the tests are carried out, which is recommended to be greater than 100lux.

\section{CONCLUSIONS}

The augmented reality provides assistance in industrial processes, simplifying identification of equipment as well as instruments and P\&ID diagrams. It enables users to manipulate and visualize elements of the process. AR is used as a guide in the calibration of industrial instruments, giving relevant information of processes that are often important to know. It may also help to skill development in the handling of industrial processes that allow control by regulation without the need to perform extra actions in the physical process, protecting both the user and the process. 


\section{ACKNOWLEDGMENT}

The authors would like to thanks to the Corporación Ecuatoriana para el Desarrollo de la Investigación y Academia -CEDIA for the financing given to research, development, and innovation, through the CEPRA projects, especially the project CEPRA-XIII-2019- 08; Sistema Colaborativo de Robots Aéreos para Manipular Cargas con Óptimo Consumo de Recursos; also to Universidad de las Fuerzas Armadas ESPE, Escuela Superior Politécnica de Chimborazo, Universidad Nacional de Chimborazo, Universidad Teconologica Indoamerica, Universidad Internacional de Ecuador and Universidad Central de Venezuela, and Grupo de Investigación en Automatización, Robótica y Sistemas Inteligentes, GI-ARSI, for the support to develop this work.

\section{REFERENCES}

[1] G. Cross y S. Rick, Technology and American Society, New York: Pearson, 2019.

[2] R. V. Krevelen y R. Poelman, A Survey of Augmented Reality, In The International Journal of Virtual Reality, vol. IX, no 2, pp. 1-20, 2010.

[3] J. Zhang, Y.-T. Sung, H.-T. Hou y K.-E. Chang, The Development and Evaluation of an Augmented Reality-Based Armillary Sphere, In Computers \& Education, vol. 73, pp. 178-188, 2014. http://doi.acm.org/10.1016/j.compedu.2014.01.003

[4] N. Imbert, F. Vignat, C. Kaewrat y P. Boonbrahm, Adding Physical Properties to 3D Models in Augmented Reality for Realistic Interactions Experiments, In Computer Science, vol. 25, pp. 364-369, 2013. DOI: http://doi.acm.org/10.1016/j.procs.2013.11.044

[5] O. Danielsson, Designing Augmented Reality Interfaces for Human-Robot Collaboration in Engine Assembly, In Research Proposal, 2016.

[6] B. Jeong y J. Yoon, Competitive Intelligence Analysis of Augmented Reality Technology Using Patent Information, In Sustainability, vol. 9, $\mathrm{n}^{\circ} 4$, p. 497, 2017. DOI: http://doi.acm.org/10.3390/su9040497

[7] A. Nee, S. Ong, G. Chryssolouris y D. Mourtzis, Augmented reality applications in design and manufacturing, In CIRP Annals, vol. 2, $\mathrm{n}^{\mathrm{o}}$ 61, pp. 657-679, 2012. DOI: http://doi.acm.org/10.1016/j.cirp.2012.05.010

[8] A. Seth, J. M. Vance y J. H. Oliver, Virtual reality for assembly methods prototyping: a review, In Virtual Reality, vol. 15, $\mathrm{n}^{\circ}$ 1, pp. 5-20, 2011. DOI: http://doi.acm.org/10.1007/s10055-009-0153-y

[9] E. A. Chicaiza, E. I. De la Cruz y V. H. Andaluz, Augmented Reality System for Training and Assistance in the Management of Industrial Equipment and Instruments, In Advances in Visual Computing, pp. 675-686, 2018. DOI: http://doi.acm.org/10.1007/978-3-030-03801-4_59

[10] M. Núñez, R. Quirós, I. Núñez, J. B. Carda y E. Camahort, Collaborative Augmented Reality for Inorganic Chemistry Education, In International Conference on ENGINEERING EDUCATION, pp. 22-24, 2008.

[11] J. Ratajczak, A. Schweigkofler, M. Riedl y D. T. Matt, Augmented Reality Combined with Location-Based Management System to Improve the Construction Process, Quality Control and Information Flow, In Advances in Informatics and Computing in Civil and Construction Engineering, pp. 289-296, 2018.

[12] J.-C. Yen, C.-H. Tsai y M. Wu, Augmented Reality in the Higher Education: Students' Science Concept Learning and Academic Achievement in Astronomy, In Procedia - Social and Behavioral Sciences, vol. 103, pp. 165-173, 2013. DOI: http://doi.acm.org/10.1016/j.sbspro.2013.10.322
[13] E. Ginter, Augmented reality use for cycling quality improvement, In Procedia Computer Science, vol. 149, pp 167-176, 2019.

DOI: http://doi.acm.org/10.1016/j.procs.2019.01.120

[14] T. M. Urakov, M. Y. Wang y A. D. Levi, Workflow Caveats in Augmented RealityeAssisted Pedicle Instrumentation: Cadaver Lab, In World Neurosurgery, vol. 126, pp. e1449e1455, 2019. http://doi.acm.org/10.1016/j.wneu.2019.03.118

[15] R. Woll, T. Damerau, K. Wrasse y R. Stark, Augmented reality in a sreious game for manual assembly processes, In Science and Technolgy Proceedings, pp. 36-39, 2011. DOI: http://doi.acm.org/10.1109/ISMAR-AMH.2011.6093654

[16] P. Vate-U-Lan, An Augmented Reality 3D Pop-Up Book: the Development of a Multimedia Project for English Language Teaching, In 2012 IEEE International Conference on Multimedia and Expo, pp. 890-895, 2012. DOI: http://doi.acm.org/10.1109/ICME.2012.79

[17] S. Fangyang, J. Jun, L. Xuejun y Q. Yue, Augmented Reality Aided Jet Engine Assembly and Disassembly Guidance System, In 4th International Universal Communication Symposium, 2010. http://doi.acm.org/10.1109/IUCS.2010.5666644

[18] H.-S. Park, H.-W. Choi y J.-W. Park, Augmented Reality based Cockpit Module Assembly System, In International Conference on Smart Manufacturing Application, pp. 130135, 2008. http://doi.acm.org/10.1109/ICSMA.2008.4505627

[19] N. G. Weng, O. Y. Bee, L. H. Yew y T. E. Hsia, An Augmented Reality System for Biology Science Education in Malaysia, In International Journal of Innovative Computing, vol. $6, \mathrm{n}^{\circ} 2,2016$.

[20] R. M. Yilmaz, Educational magic toys developed with augmented reality technology for early childhood education, In Computers in Human Behavior, vol. 54, pp. 240-248, 2016. DOI: http://doi.acm.org/10.1016/j.chb.2015.07.040

[21] P. Chanthanakone y C. Sandor, Augmented Reality and Animation in Thailand Context, In Communication and Media in Asia Pacific (CMAP), vol. 1, n $\mathrm{n}^{\mathrm{0}} 1,2018$.

[22] D. Tatić y T. Bojan, The application of augmented reality technologies for the improvement of occupational safety in an industrial environment, In Computers in Industry, vol. 85, pp. $1-10$, 2017. http://doi.acm.org/10.1016/j.compind.2016.11.004

[23] M. F. Alam, S. Katsikas, O. Beltramello y S. Hadjiefthymiades, Augmented and virtual reality based monitoring and safety system: A prototype IoT platform, In Journal of Network and Computer Applications, vol. 89, pp. 109-119, 2017. http://doi.acm.org/10.1016/j.jnca.2017.03.022

[24] H. Borgmann, J. Salem, M. R. Socarrás y I. Tsaur, Feasibility and safety of augmented reality-assisted urological surgery using smartglass, In World Journal of Urology, vol. 35, $\mathrm{n}^{\circ} 6$, p. 967-972, 2017. DOI: http://doi.acm.org/10.1007/s00345016-1956-6

[25] X. Li, Y. Wen, H.-L. Chi, X. Wang y A. P. Chan, A critical review of virtual and augmented reality (VR/AR) applications in construction safety, In Automation in Construction, vol. 86 , pp. 150-162, 2018.2 http://doi.acm.org/10.1016/j.autcon.2017.11.003

[26] K. Ogata, Modern Control Engineering, Person, 2002.

[27] Autodesk Inc., Autodesk, [En línea]. Available: https://www.autodesk.com/products/maya/overview.

[28] Sauro, J., Lewis, J.R.: When designing usability questionnaires, does it hurt to be positive In: Proceedings of the SIGCHI Conference on Human Factors in Computing Systems, pp. 2215-2224. ACM, May 2013. 